UDK: 821.134.2(85).09-31 Варгас Љоса М. DOI: https://doi.org/10.18485/legado_hispanico.2020.ch13

\author{
Mirjana Sekulić ${ }^{1}$ \\ Universidad de Kragujevac \\ Serbia
}

\title{
BARBARIE Y DESPERTAR DEL HÉROE EN LA NOVELA EL SUEÑO DEL CELTA DE MARIO VARGAS LLOSA ${ }^{2}$
}

\begin{abstract}
Resumen
En el presente trabajo se interpretan varios aspectos de la novela $E l$ sueño del celta (2010) de Mario Vargas Llosa, tomando en consideración teorías poscoloniales y las actitudes del escritor peruano sobre diferentes cuestiones, expresadas en sus ensayos, entrevistas y artículos. El punto de partida son las ideas de Vargas Llosa sobre la literatura e historia, el deber moral del escritor ante la historia, junto con la necesidad de superar el conformismo. En base a ello cuestionamos cómo la novela El sueño del celta inicia varias preguntas sobre el colonialismo, las fronteras entre la barbarie y la civilización, el despertar de los héroes, la posibilidad de lograr la libertad, etc. El artículo se centra en la compleja realidad colonial presentada en la novela, profundizando en el cuestionamiento de responsabilidades y víctimas de la gran misión civilizadora en Congo y Amazonia. El protagonista es interpretado en relación con el viaje,

\footnotetext{
${ }^{1}$ msekulic@filum.kg.ac.rs

${ }^{2}$ El artículo representa un estudio ampliado y corregido de la ponencia en el Simposio internacional dedicado a Mario Vargas Llosa en Budva (Montenegro, 2015). La ponencia fue publicada en el libro Književni plamen Marija Vargas Ljose bajo el título «Pristupi temi kolonijalizma u romanu Keltov san Marija Vargasa Ljose» (v. Sekulić 2017).
} 
físico y simbólico, observando los cambios producidos en su personalidad por las interacciones en el ambiente colonial. Reflexiones sobre la identidad y el comportamiento del protagonista llevan hacia conclusiones sobre la concepción del héroe en la obra, así como hacia una comprensión del papel que Vargas Llosa le da a la ficción en relación con la libertad colectiva y personal.

Palabras clave: Mario Vargas Llosa, El sueño del celta, colonialismo, barbarie, héroe, libertad, literatura.

A pesar de los cambios producidos durante su larga trayectoria literaria, Mario Vargas Llosa sigue apoyando la actitud de su antiguo modelo literario Sartre de que el escritor debe preocuparse por los problemas de su tiempo. El novelista e intelectual tiene deber moral ante las exigencias de la historia y la política (Oviedo 1993: 85). La literatura no debe ser conformista, según dice Vargas Llosa en el discurso del Premio Rómulo Gallegos en 1967, sino que debe ir estimulando la voluntad de cambiar el mundo para mejor. La novela representa un desafío a lo existente y recuerda a los lectores que el mundo no está hecho bien, por lo tanto, puede ser mejor (Vargas Llosa 2011). Muchos años después, en el discurso de Nobel, Llosa (2010c) repitió la misma idea sobre la relación compleja y estrecha entre la historia y la literatura: «Lo quieran o no, lo sepan o no, los fabuladores, al inventar historias, propagan la insatisfacción, mostrando que el mundo está mal hecho [...]». Es la misma idea sobre ficción que planteó en el texto El arte de mentir escrito para la Revista de la Universidad de México en 1984: «En el corazón de todas ellas llamea una protesta» (Vargas Llosa 1984: 4). En el ensayo La verdad de las mentiras (1990) también dice:

[...] la literatura es el reino por excelencia de la ambigüedad. Sus verdades son siempre subjetivas, verdades a medias, relativas, verdades literarias que con frecuencia constituyen inexactitudes flagrantes o mentiras históricas. [...] Pero, aunque esté repleta de mentiras —o, más bien, por ello mismo - la literatura cuenta la historia que la historia que escriben los historiadores no sabe ni puede contar. Porque los fraudes, embaucos y exageraciones de la literatura narrativa sirven para expresar verdades profundas e inquietantes que sólo de esta manera sesgada ven la luz (Vargas Llosa 2007: 24-25).

Siguiendo a Balzac, Llosa (2007: 32) percibe la novela como una historia privada. El autor se concentra en lo menos conocido, el mundo 
privado, pensamientos, sentimientos, motivos menos conocidos para actuar de los personajes. La novela narra lo que la historia no puede, puesto que la vida no consiste únicamente en acontecimientos públicos escritos en registros, sino también en lo que sucede en la consciencia humana. Brian McHale en Postmodern narrative (1996) se refiere a ello como lugares oscuros de historia, una de las características de la narrativa posmoderna y nueva novela hispanoamericana, mientras que Llosa los denomina "grandes zonas de sombras», accesibles por medio de intuición y especulación y en las que se halla el material narrativo de novelista. Su papel entonces es rellenar los vacíos existentes (Vargas Llosa 2004: 28), porque hay verdades en la vida que no son soportables, por siguiente, justifican la invención de mentiras y ficción (Vargas Llosa 2001). Las novelas no narran la vida, el autor explica, sino que la cambian y transforman de acuerdo con la imaginación del autor. Las mentiras narradas en las novelas por lo tanto sirven para completar eficazmente o superar las limitaciones e imposibilidades de la vida real. Asimismo, la literatura representa un cuestionamiento radical del mundo en el que vivimos (Vargas Llosa 2000), mediante elemento añadido que, según teorías de Llosa, se refiere a la crítica y otro sentimiento que añade el autor a la realidad plasmada en la obra (Soldatić 2002: 212-213). ${ }^{3}$ De esta manera, a diferencia de libros históricos y reportajes periodísticos que Vargas Llosa siempre utiliza como materia y fuente para sus obras literarias, las novelas o la ficción representan una rebelión y superación de la vida (Vargas Llosa 2007: 20). Son los demonios personales, históricos y culturales los que estimulan al escritor a crear un mundo paralelo al real, en el que se deconstruye el discurso con pretensiones de reconstruir fielmente el pasado. En ese proceso el autor reescribe la historia desde el punto de vista de los marginados.

Teniendo en cuenta estas propuestas teóricas, proponemos cuestionar la novela El sueño del celta, centrándonos en sus principales aspectos relacionados con la crítica colonial ambientados en Congo: fronteras entre la barbarie y civilización, héroes, libertad, utopía, maldad humana, etc.

Esta novela publicada en 2010 desarrolla la historia de Roger Casement, un personaje histórico, un diplomático británico de origen irlandés, en sus viajes a Congo y Perú, donde observando escenas de violencia y exploatación de los indígenas descubre el lado oscuro de la existencia humana. Casement se rebela contra el sistema de injusticias

\footnotetext{
${ }^{3}$ Dalibor Soldatić en el estudio Prilozi za teoriju novog hispanoameričkog romana define
} las ideas novelescas y técnicas narrativas Mario Vargas Llosa (v. Soldatić 2002: 189-215). 
cuyos autores son la compañía belga del rey Leopoldo II en Congo y la compañía británica bajo el liderazgo de Julio Arana en Perú. Escribe informes que sacudieron la opinión pública y contribuyeron que Joseph Conrad, autor de la gran novela de colonialismo en Congo, El corazón de las tinieblas, lo denominara Bartolomé de las Casas británico. Precisamente tomando como base la novela de Joseph Konrad, Vargas Llosa una vez más denuncia la atrocidad del colonialismo presentando la vida y aventuras de Casement. Las Casas escribió Brevísima relación de la destrucción de las Indias en la que acusa a los conquistadores españoles de crímenes sobre los indígenas, obra que contribuyó a crear la «leyenda negra» de la conquista de América. Las Casas, nos recuerda Tzvetan Todorov (2010: 37-38), fue el primero en cuya obra apareció la reflexión sobre el bárbaro como extranjero incomprensible y el bárbaro como persona cruel.

Como subraya Efraín Kristal (2012: 131)4, Llosa en la primera década del siglo XXI ya no cree en la acción revolucionaria, pero el dolor y perspicacia con los que diagnosticó la sociedad en los años 60 regresan a sus novelas, lo mismo que los «personajes que desafían o huyen de las injusticias de las comunidades humanas plagadas de violencia y abuso». Llosa en ese periodo continúa preocupado por los luchadores por la utopía, pero ya no los presenta como fanáticos desesperados con convicciones grotescas. Empieza a tratarlos con cuidado y compasión, intentando investigar el sufrimiento de los individuos que se convirtieron en los enemigos del mundo (Kristal 2012: 131).

Casement, como afirma Llosa, es uno de los personajes idóneos para ser representados en la novela histórica, dada su vida tumultuosa, controvertida, llena de aventuras, que presenta muchas zonas oscuras para ser recreadas en la novela y hacer sus lectores reflexionar sobre la historia, es decir, una realidad compleja, ambigua y contradictoria a la que no se puede acceder con certeza.

\section{¿Cómo se llega a la barbarie?}

El autor reconstruye la historia colonial en Congo y Amazonia, al mismo tiempo deconstruyéndola y demostrando que no existe una sola mirada autoritaria hacia el pasado. Siguiendo el ejemplo de Camus, Llosa

\footnotetext{
${ }^{4}$ El mismo autor considera que a principios del siglo XXI podemos observar una tercera etapa en la trayectoria literaria de Llosa, después del optimismo relacionado con el socialismo en los años 60 y las democracias liberales en los años 80. Esta etapa abarca las novelas: La fiesta del Chivo (2000), El paraíso en la otra esquina (2003), Travesuras de la niña mala (2006) y El sueño del celta (2010).
} 
presenta distintas perspectivas sobre cuestiones problemáticas, con el fin de evitar lugares comunes sobre los colonizadores y colonizados, frecuentes en los debates poscoloniales. Varias obras de Llosa tienen en común el proceso de exploración y descubrimiento paulatino de la(s) verdad(es) sobre los acontecimientos históricos y las personalidades que los protagonizaban. Para ello usaba las técnicas narrativas de caja china, vasos comunicantes y dato escondido, señalando la fragmentariedad y subjetividad de las verdades históricas. Teniendo en cuenta que la focalización es una de las principales cuestiones en la crítica poscolonial, en El sueño del celta la historia está focalizada desde la perspectiva del protagonista, que, en busca de la verdad colonial, da palabra a distintos testigos, colonizadores y colonizados. El protagonista da prioridad a testimonios personales, recuperando el proceso de investigación y construcción de la verdad. De esta manera también se explora la falta de discurso de los subyugados y a la vez se descubre la verdad cuestionable, dada la personalidad del protagonista de la historia. Pozuelo Yvancos (2013) explica que «en el fondo la estructura narrativa de Vargas es acumulativa, va avanzando con ambición de poseer los datos como si la novela propiamente se adaptara la estructura de un Informe. En cierto modo el mismo Vargas Llosa hace otro Informe, el Informe Vargas Llosa».

La novela plantea el famoso debate de oposiciones entre el Primer y el Tercer / los Terceros mundos, metrópoli y colonias, centro y periferias, civilización y barbarie, así como las libertades nacionales y coloniales al mismo tiempo que las personales. El inicio de la novela presenta inconfundiblemente la postura europea ante la situación colonial en Congo, los estereotipos y lugares comunes del colonialismo, expresados de mejor manera en palabras de Stanley Morton, famoso explorador y periodista británico, colaborador del rey Leopoldo II de Bélgica en las explotaciones africanas, sobre la santa trinidad de las tres «C»: cristianismo, civilización, comercio (Vargas Llosa 2010a: 43). El discurso occidental además justificaba la presencia de las compañías europeas en África y Amazonia por la existencia de otros pueblos que esclavizaban a aquellos que los europeos, en apariencia, defendían. Es el discurso eurocentrista que legitimaba la explotación, como otra cara o la cara oculta de la misión civilizadora. La salvación de los congoloses, no obstante, fue pagada por la eliminación de libertad en nombre de ideales abstractos de la civilización.

Pavel Markovski (2009: 607), analizando el discurso colonial, explica que los Otros fueron percibidos como seres exóticos y raros, inferiores, que deberían ser emancipados por los europeos. Es un discurso 
que no surge de la necesidad de conocer al Otro, sino para establecer jerarquías. Los acontecimientos iniciales de la novela El sueño del celta presentan claras fronteras entre los europeos y los congoleses, así como las fronteras entre los civilizados y los bárbaros, basadas en la supuesta superioridad racial. El personaje de Stenly Morton lo expresa claramente:

\begin{abstract}
Vendrán misioneros que los sacarán del paganismo y les enseñarán que un cristiano no debe comerse al prójimo. Médicos que los vacunarán contra las epidemias y los curarán mejor que sus hechiceros. Compañías que les darán trabajo. Escuelas donde aprenderán los idiomas civilizados. Donde les enseñaran a vestirse, a rezar al verdadero Dios, a hablar en cristiano y no en esos dialectos de monos que hablan. Poco a poco reemplazarán sus costumbres bárbaras por las de seres modernos instruidos. Si supieran lo que hacemos por ellos nos besarían los pies (Vargas Llosa 2010a: 43).
\end{abstract}

Como explica Markovski (2009: 607), el discurso crea imágenes de la realidad en las cuales las autoridades basan sus pretensiones imperialistas, aunque el poder es el que influye en las formas de discurso. Este discurso se caracteriza por los estereotipos y clichés, que excluyen al otro, estableciendo una frontera simbólica entre lo aceptable e inaceptable, lo que pertenece y lo que no pertenece (Hall 2010: 430). Las fronteras, sin embargo, siempre son inestables, borrosas, de ahí imaginadas y utilizadas para simplificar la realidad e intensificar la alteridad. Las únicas fronteras entre los europeos y los otros son creadas por la estereotipación basada en el proceso de representación de las diferencias, nos explica Stuart Hall (2010: 430). La estereotipación, según el mismo teórico, además es práctica de exclusión, instrumento de poder que clasifica las personas y las excluye.

El otro congolés tiene la identidad más pronunciada en el discurso de Stanley Morton, que lo describe como el otro, por oposición al europeo y civilizado, superior, como una identidad fijada de antemano. Siguiendo ideas de M. Foucault, Hall (2018: 35) explica que el discurso tiene verdaderos efectos en la práctica, o sea, una descripción llega a ser verdadera por medio del discurso. Si creemos que alguien es tal y como lo describimos, al final llega a ser lo que pensamos. Los europeos se comportan como si los congoleses no tuvieran conocimientos, capacidades para pensar y hablar. Llega a ser justificado el decir de Stanley Morton: «Por eso nosotros decidimos por ellos lo que les conviene. [...] Todo esto es por su bien, claro que sí» (Vargas Llosa 2010a: 43).

La negación del Otro, su consideración como si no fuera humano o no humano del todo es típica, según Tzvetan Todorov (2010: 33), de los 
bárbaros. De hecho, los bárbaros son los que, independientemente del tiempo y lugar, valoran a otros como radicalmente distintos o se comportan con ellos de forma bárbara, los tratan como a monstruos, salvajes (Todorov 2010: 35-36). El miedo a los bárbaros es lo que convierte a la gente en bárbaros. Así se puede explicar el comportamiento de los colonizadores europeos, que explotaban mano de obra de congoleses y acompañaron esa explotación de caucho con violencia irrefrenable, cruzando fronteras entre la civilización y la barbarie. Este comportamiento, en palabras de Llosa (2001), es la peor forma de barbarie, puesto que se trata de una barbarie consciente e interesada.

A pesar de plantear la situación colonial de esta manera, Llosa no esquematiza la representación de las cuestiones coloniales, es más, señala la necesidad de observarlas desde distintos puntos de vista, cuestionando cada fuente de «verdad». Según Llosa, a través de Alice Stopford Green, uno de los personajes de su obra, la novela de Conrad «es una parábola según la cual África vuelve bárbaros a los civilizados europeos que van allá» (Vargas Llosa 2010a: 76), siguiendo la famosa crítica que Chinua Achebe, escritor nigeriano, hizo de la obra de Conrad (v. Kölmann 2014: 259). No obstante, para Llosa, no se trata de Congo u otro lugar en concreto. El escritor peruano se pregunta sobre los factores que hicieron que los europeos, como representantes de la civilización, cruzaran la frontera humana y/o geográfica hacia la barbarie. La pregunta que hace es si los europeos fueron cambiados por el espacio africano, «el corazón de las tinieblas», según la denominación de Conrad, o si Congo fue el espacio de libertad en el que no se conocían y no se respetaban las leyes de los indígenas, mientras que las leyes europeas estaban lejanas y no aplicables en el contexto congolés. Llosa apunta a la idea de la deshumanización del hombre que viaja a los territorios desconocidos de África, donde, al parecer, no se respetan los principios aceptados en Europa. Interpretando el salvajismo institucionalizado en la novela El sueño del celta V. Kanev (2017) concluye con una reflexión similar que «la maldad domina al hombre, pero en Europa está disimulada, controlada por el sistema de leyes y normas». La distancia física, nos demuestra la novela, tiene efectos liberadores y Llosa lo ejemplifica no solo en los colonizadores en general sino en el personaje de Casement en particular, dado que se sentía más libre cuando estaba alejado de su patria. En palabras de uno de los personajes:

El África, aquel continente atroz, pero hermosísimo, de enormes sufrimientos, era también tierra de libertad, donde los seres humanos 
podían ser maltratados de manera inicua, pero, asimismo, manifestar sus pasiones, fantasías, deseos, instintos y sueños, sin las bridas y prejuicios que en Gran Bretaña ahogaban el placer (Vargas Llosa 2010a: 280-281).

La civilización y libertad llegaron a ser diametralmente opuestos.

Congo, nos revela la novela, ha sido solo una excusa para expresar la horrible visión católica sobre el mal absoluto, presente en todas partes y siempre. Según la interpretación de Llosa, los colonizadores no tenían la capacidad de diferenciar el bien y el mal, lo humano y no humano: «Si algo he aprendido en el Congo, es que no hay peor fiera sanguinaria que el ser humano. [...] en materia de crueldad humana, no había límites, que siempre era posible ir más allá inventando maneras de infligir tormento al prójimo» (Vargas Llosa 2010a: 98, 95). Para Llosa el mal, a pesar de su origen, es algo que existe desde siempre, independientemente a progreso material y científico, incansable tanto en la civilización como en la barbarie (Vargas Llosa 2010b). En la novela de Llosa encontramos ideas de Tzvetan Todorov (2010: 80) de que ninguna cultura es bárbara en sí misma, así como que ningún pueblo es definitivamente civilizado. Todos pueden convertirse tanto en civilizados como en bárbaros, porque es algo propio de la especie humana.

El informe de Casement demostró que fueron los europeos los que llevaron consigo la mayor barbarie a África. Los personajes novelísticos de Llosa no reciben características bárbaras al ahondar en las selvas africanas, es más, el protagonista Casement, en palabras de su amiga, adquirió en África el mayor grado de civilización del que había tenido antes de su viaje (Vargas Llosa 2010a: 76).

Años después, en la duermevela visionaria de la fiebre, se ruborizaba pensando en lo ciego que había sido. Ni siquiera se daba bien cuenta, al principio, de la razón de ser de aquella expedición encabezada por Stanley y financiada por el rey de los belgas, a quien, por supuesto, entonces consideraba - como Europa, como Occidente, como el mundo- el gran monarca humanitario, empeñado en acabar con esas lacras que eran la esclavitud y la antropofagia y en liberar a las tribus del paganismo y las servidumbres que las mantenían en estado feral (Vargas Llosa 2010a: 38).

Mientras que Joseph Conrad exploraba los cambios mentales que se observaban en los colonizadores en África, Mario Vargas Llosa se centra en los que tenían consciencia y estaban conscientes de lo que ocurría en África. Su protagonista Casement, al indagar en los acontecimientos con el fin de hacer el informe del colonialismo, presentó varias cuestiones sobre 
los colonizadores conscientes e inconscientes, cuya responsabilidad se perdía en jerarquías y sistemas, manipulaciones y órdenes, presencia y distancia de los hechos ocurridos. En este mundo caótico donde se pierden o transgreden las fronteras entre los bárbaros y civilizados, destacándolas y poniéndolas en el primer plano, es donde se establece la identidad personal y colectiva. También es el lugar donde la realidad caótica y compleja no deja percibir la responsabilidad de las crueldades.

Para estas cuestiones de responsabilidad colonial hay que tener en cuenta que Llosa, bajo la influencia de Sartre, considera que el bien y el mal no son conceptos abstractos, sino objetos de elección (Oviedo 1993: 87). La persona que actúa por voluntad propia cuando elige algo, no sigue una norma impuesta para liberarse de responsabilidad o para reducirla, explica en continuación Oviedo. Solo así cobra autenticidad. Escribiendo el informe, Casement, o Llosa a través de Casement, abre un debate sobre las prácticas coloniales, mostrando que nadie asume la responsabilidad, es más, la transfiere a otras personas, directa o indirectamente. El grado de culpa no coincide con el grado de jurisdicción en el sistema colonial, se pierde en su compleja red de órdenes y cumplimientos.

El único personaje que, a partir de un momento determinado, hace una elección de forma consciente, es Roger Casement. Sin embargo, incluso él pone excusas y límites a sus competencias y jurisdicción:

Mientras, aguantando las náuseas, lo escuchaba, se decía que no estaba en Bolobo para hacer de justiciero, sino para investigar y acumular información. Mientras más exacto y completo fuera su informe, más efectiva sería su contribución a luchar contra esta maldad institucionalizada que se había vuelto el Congo. [...] El informaría sobre esas injusticias y crímenes y Gran Bretaña y sus aliados exigirían al Gobierno belga que pusiera fin a los abusos y castigara a los torturadores y criminales (Vargas Llosa 2010a: 90-92).

Teniendo en cuenta la interpretación que hace Llosa de la moral de los límites de Camus, concepto según el que no se puede llegar a la verdad sin dejar que hablen los oponentes y sin comprender sus argumentos, el protagonista intenta escuchar a todos los involucrados en la violencia y explotación para llegar a la verdad colonial. Interrogando a distintas personas involucradas en el colonialismo, de distinto origen y de distintas posiciones jerárquicas, Llosa demuestra que el salvajismo es institucionalizado, y en ese sistema la culpa y la responsabilidad son borrosas, perdiendo estatus de lo indudable. Incluso el protagonista, 
Casement, tenía «la sensación de que nadie llegaba al fondo de las cosas, que incluso las gentes mejor intencionadas le ocultaban algo y se lo ocultaban a sí mismos, temerosos de enfrentar una verdad terrible y acusadora» (Vargas Llosa 2010a: 83-84). De todos los interrogados Casement recibe el mensaje de que nada cambiará y de que su esfuerzo no sirve para nada. Sin embargo, él decide luchar, llevado por la ilusión y el deseo de ordenar el mundo caótico.

\section{Los Otros y el despertar del héroe}

En un contexto en el que los congoleses están obligados a trabajar y cumplir con normas de cantidad de caucho recogido bajo castigo violente o bajo amenaza de violencia, Vargas Llosa pone énfasis no solo en la violencia física sino en los efectos psicológicos de mayor alcance. Ante todo, concluye que el valor del Otro, subyugado, está reducido a mano de obra o instrumento físico que contribuye al desarrollo económico de los países europeos, mientras que como bárbaro le son negadas las capacidades intelectuales y el poder de hablar. La mayor impresión en el protagonista deja la escena del Otro, paralizado por el miedo y la confusión, con la fuerza de voluntad debilitada por la violencia constante, que se comporta como un autómata, con la mirada perdida: «Se sorprendió de que ninguno de esos pobres seres se quejara de lo principal: ¿con qué derecho habían venido esos forasteros a invadirlos, explotarlos y maltratarlos?» (Vargas Llosa 2010a: 98). La única circunstancia preocupante fue la cantidad de caucho que no lograban recoger.

La novela señala que no solo las instituciones, tradición y costumbres congolesas fueron denegadas, sino la dignidad humana también. Además, la novela a continuación demuestra la negación discursiva de la diversidad cultural y racial por parte de los colonizadores europeos -el Otro es igual en Congo y Perú-. Es el bárbaro, por lo tanto, objeto de la misma violencia en nombre de ideales civilizadores.

Según Pavel Markovski (2009: 606), la actitud poscolonial expresa un desacuerdo con la pasividad ante el poder imperial. Esta pasividad colonial es observada por el protagonista de la novela El sueño del celta en Congo y en cierto sentido se convierte en el polo opuesto al comportamiento de Casement. La falta de reacción y protesta que Casement observaba en los «autómatas, seres espectrales», visión de los congoleses subyugados, enfatiza sus propias respuestas a tal situación, convirtiéndolo en defensor de los derechos humanos, rebelde contra el sistema colonial. Su lucha tiene origen en la falta de reacción defensora de 
los congoloses, con lo que nace la figura del héroe. En su actitud podemos reconocer la preocupación y responsabilidad que, según Levinás (1998: 296), el centro debe tener hacia la periferia. A pesar de tener dudas y no presentar un comportamiento indudablemente heroico, Casement en parte se sacrifica, con lo que su aventura vital cobra sentido, dado que, según Augé (1996: 24), la identidad de individuo es determinada por su posición en el sistema de relaciones con otros. Cada individuo es incompleto y heterogéneo, desarrollándose de acuerdo con las interacciones nuevas. Al iniciar el viaje a África, Casement creía en los ideales del colonialismo e imperio. Sin embargo, lo que presenció en Congo durante los primeros seis meses, despertó en él inquietudes en relación con la naturaleza humana.

Según Llosa (2010a: 156), su protesta nació «porque creía que el mundo, la sociedad, la vida, no podían seguir siendo esa vergüenza». En Roger Casement también reconocemos al utopista, dado que la utopía está relacionada con un momento histórico determinado, que en el utopista produce el deseo de expresar su descontento y rebeldía, sin poder estar indiferente ante lo que percibe en la sociedad (Servije 2005: 276). Varios héroes de Llosa se despiertan de esta manera.

Partiendo de las teorías de Claude Lévi-Strauss, Hugo Francisco Bauzá, Guillermo Echevarría Molloy y otros, D. Quintana González (2017: 20-29) en su tesis define al héroe con las siguientes características: el móvil de su acción es ético, el héroe es regido por la ilusión o utopía deseando ordenar el mundo. Al combatir arriesga su vida, sin importar si triunfa o fracasa. Es transgresor y buscador, así como mediador entre lo civilizado y lo salvaje, cuyas acciones son ambiguas. En todo ello está condenado a estar solo. En todas las características podemos reconocer al héroe de la novela El sueño del celta.

Es posible observar la vida de Roger Casement en relación con los viajes: desde escuchar las historias de los espacios exóticos de su padre, imaginarlos en la mente juvenil, hasta viajar a África y América del Sur. Según el estudio de Friedrich Wolfettel (2005: 11) sobre relatos de viajes y estructura mítica, todo viaje es descubrimiento, lo que incluye el descubrimiento interior, «aprendizaje y transformación mental del yo descubridor». Viajar es «establecer una conexión entre estos aspectos exteriores y el yo secreto», continúa el mismo autor (Wolfzettel 2005: 11). El viaje, así pues, descubre al Otro y en relación con él uno descubre a sí mismo. Roger Casement viaja a África con deseo de conocer los territorios exóticos de los que escuchaba en su niñez, confiando en las misiones coloniales, mientras que su viaje «al corazón de las tinieblas» 
termina en decepción. En este viaje ocurre la iniciación del personaje que, al conocer la realidad colonial llega a desilusionarse, rompe con las actitudes y el optimismo anteriores. Casement descubre la naturaleza del ser humano en las escenas de violencia y crueldad humana, que le motiva a romper el silencio dominante en las colonias. La pasión por la lucha y defensa de los derechos humanos de los congoleses que despierta en él, según otros personajes novelísticos de Llosa, presentados como europeos ilustrados (por ejemplo, Henry Morton Stenley), se debe a su debilidad. Esta debilidad de Casement, de hecho, es lo que Todorov (2010: 40) reconoce como rasgos de los civilizados - la capacidad de reconocer la humanidad de otros, es decir, aceptar a ver a otros como portadores de lo humano, igual que nosotros-.

Al cuestionar las debilidades del protagonista de la novela, cabe mencionar uno de los datos escondidos de la técnica narrativa de Llosa. Con el desarrollo de la novela se descubre la supuesta homosexualidad de Casement. Según la recreación novelística de Llosa, y en base a los diarios del protagonista, sale a la luz que Casement se siente atraído por el cuerpo fuerte de los congoleses. Este hecho, conocido cuando fueron descubiertos sus diarios, afectará la comprensión y el desprestigio de sus actos heroicos. El individuo se forma en relación con las elecciones que hace, pero el significado de sus actos no siempre depende de su voluntad sino de la percepción de los demás que determinan su valor (Oviedo 1993: 85-90). Así, Casement termina como traidor del imperio británico, marginalizado por sus tendencias homosexuales, víctima del proyecto social que inició solo.

Mario Vargas Llosa, en interpretación de María Del Valle Manríquez (2015: 177), ha recreado la historia de Casement, porque este personaje histórico fue silenciado por la campaña de desprestigio que había llevado el servicio de inteligencia británico. Llosa, en defensa de Casement, pronuncia la famosa definición del héroe al final de la novela: «[...] un héroe y un mártir no es un prototipo abstracto ni un dechado de perfecciones sino un ser humano, hecho de contradicciones y contrastes, debilidades y grandezas, ya que un hombre, como escribió José Enrique Rodó, 'es muchos hombres', lo que quiere decir que ángeles y demonios se mezclan en su personalidad de manera inextricable» (Vargas Llosa 2010a: 449). Los héroes de Llosa están marcados por dudar de sus propias observaciones, posibilidades y objetivos, mientras que su lucha no queda libre de contrariedades. H. C. Weldt Basson (2013: 232) describe a Casement como «saint and sinner, as both colonizer and colonized», en lo que reside su contradicción posmoderna. 
Los héroes que Llosa elige para que sean protagonistas de sus novelas no son grandes personajes históricos con biografía impecable, sino las personalidades contradictorias, disociadas, que en su compleja personalidad tienen algo heroico - fe y determinación-. Casement es uno de los héroes conscientes del camino que eligieron y cuyas obras, incluyendo sus utopías o sueños, tuvieron eco en la historia, a pesar de sus éxitos o fracasos. Su heroísmo, desde su propia perspectiva, no es un acto idealizado, sino una necesidad interior de protestar contra algo que debería conmover a la sociedad en general.

Los actos de Casement en Congo también son cuestionables dado que este héroe se limita a la liberación de la violencia, sin negar la naturaleza bárbara de los congoleses y su inferioridad, sin tampoco negar los efectos positivos de la presencia europea en Congo. Según Kristal (2012: 146), Llosa presenta a Casement como un personaje que no consigue convicciones completas y que parece jugar diferentes papeles, incapaz de identificarse con ellos. Recordemos que en el texto que sobre Camus y la moral de los límites Llosa expresa que «la experiencia moderna nos muestra que disociar el combate contra el hambre, la explotación, el colonialismo, del combate por la libertad y la dignidad del individuo es tan suicida y tan absurdo como disociar la idea de la libertad de la justicia verdadera, aquella que es incompatible con la injusta distribución de la riqueza y de la cultura» (Vargas Llosa 1976). Las luchas por la decolonización, como las presenta el escritor en El sueño del celta, con frecuencia olvidaban estos aspectos de la vida de los colonizados.

\section{Libertad y ficción}

Además de ser defensor de los derechos humanos en el contexto colonial, Roger Casement posee otro sueño, el de la libertad personal, ser lo que es. Este sueño estuvo reprimido en Europa y se ha realizado parcialmente en las colonias, lejos de las convenciones sociales europeas. Sin embargo, este personaje, según se entiende de la novela de Llosa, solo consigue la verdadera liberación escribiendo diarios, en parte ficción que contiene deseos sexuales no realizados, sin embargo, descritos como reales. Los diarios de Casement representan la respuesta de la imaginación de un individuo descontento ante la derrota de la vida cotidiana. En estos diarios se confirman palabras de Mario Vargas Llosa (2011: 32), de que la mentira como elemento añadido es lo que diferencia la ficción de la historia o de la realidad, mientras que las palabras convincentes construyen un mundo paralelo en el que el individuo 
encuentra refugio de las limitaciones impuestas en la vida. La ficción de Roger Casement se convierte en un espacio reservado para la realización de las utopías personales, en el que el individuo puede expresar todos sus deseos, instintos, pasiones y fantasmas, todo lo que niega y oculta en la vida pública. La ficción es la manera para vivir más de una vida y gracias a ella, el individuo puede encontrar la parte perdida de su personalidad. Asimismo, la ficción permite que la vida social se desarrolle sin interrumpir, que se mantenga fuera del caos y violencia.

Mario Vargas Llosa tiene confianza en el papel de la ficción y la literatura. El escritor peruano, igual que Homi Bhabha (2002: 29), parte de la idea de que el escritor o el crítico «debe intentar comprender plenamente, hacerse responsable de los pasados no dichos, no representados, que habitan el presente histórico». En la novela El sueño del celta aparece el tono moralizador, no tan habitual en las obras anteriores de Llosa, según I. Enkvist (2012: 101), pero el que estará presente en sus obras posteriores, como El héroe discreto. La sociedad libre necesita individuos con sentido crítico y responsables, conscientes de que el mundo en el que vivimos debe estar cuestionado constantemente, con el fin de acercarlo a la visión del mundo que deseamos, a pesar de sus rasgos quiméricos. El valor de la imaginación en la historia es múltiple, porque la ficción sirve para aplacar deseos y miedos, haciendo que el individuo sea ambicioso y transgrede las circunstancias impuestas. La imaginación y los intentos para acercarla a la realidad a través de rebeldes solitarios y a veces fracasados es lo que ha producido descubrimientos y el desarrollo histórico (Vargas Llosa 2011: 30-31). El héroe tiene el mismo papel que el escritor -luchar a pesar de las derrotas-. En una entrevista, aunque habla de la novela El paraíso en otra esquina, Vargas Llosa (2003) repite la idea subyacente en la novela El sueño del celta: «Yo soy un utópico en todo menos en política. [...] Hay que buscar la perfección en la creación, en la vocación, en el amor, en el placer. Pero todo eso en el campo individual. No colectivo, no tratar de traer la felicidad a toda la sociedad». En estas palabras podemos encontrar el error que cometió Roger Casement, intentando iniciar la revolución y acabar con el colonialismo que él percibía en su patria Irlanda, acabando a su vez como traidor a pesar del mérito de sus Informes sobre el colonialismo en Congo y Amazonia. 


\section{REFERENCIAS BIBLIOGRÁFICAS}

Augé 1996: Marc Augé. El sentido de los otros. Actualidad de la antropología. Barcelona / Buenos Aires / México: Paidós.

Bhabha 2002: Homi K. Bhabha. El lugar de la cultura. Buenos Aires: Ediciones Manantial.

Del Valle Manriquez 2015: María del Valle Manriquez. «El sueño del celta, de Mario Vargas Llosa; ¿Referencialidad factual y/o literaria?». Daniel Altamiranda (ed.), Escultura, cultura y referenciamiento, Buenos Aires: Editorial Dunken, 161-179.

Enkvist 2012: Inger Enkvist. «Vargas Llosa: El sueño del celta y el debate político de los años 60 y 70». Revista hispanocubana, 43: 100-112. Web. 10/09/2015.

Hall 2010: Stuart Hall. Sin garantías: Trayectorias y problemáticas en estudios culturales. Popayán: Instituto de estudios sociales y culturales Pensar / Universidad Javeriana / Instituto de Estudios Peruanos / Universidad Andina Simón Bolívar sede Ecuador / Envión Editores.

Hol 2018: Stjuart Hol. Zapad i ostatak sveta: Diskurs i moć. Loznica: Karpos. Kanev 2017: Venko Kanev. «El salvajismo institucionalizado en El sueño del celta de Mario Vargas Llosa». América [Online], 50: 85-94. Web. $01 / 02 / 2020$.

Kölmann 2014: Sabine Kölmann. A companion to Mario Vargas Llosa. Woodbridge: Tamesis.

Kristal 2012: Efraín Kristal. «From utopia to reconciliation: The Way to Paradise, The Bad Girl and The Dream of the Celt». Efraín Kristal \& John King (eds.), The Cambridge Companion to Mario Vargas Llosa, New York: Cambridge University Press, 129-147.

Levinas 1998: Emanuel Levinas. Među nama: misliti-na-drugog: ogledi.

Sremski Karlovci / Novi Sad: Izdavačka knjižarnica Zorana Stojanovića.

Markovski 2009: Mihal Pavel Markovski. «Postkolonijalizam». Ana Bužinjska \& Mihal Pavel Markovski, Književne teorije XX veka, Beograd: Službeni glasnik, 603-621.

Mekhejl 1996: Brajan Mekhejl. «Postmoderna proza». Reč, 28: 105-120. Oviedo 1993: José Miguel Oviedo. «Vargas Llosa entre Sartre y Camus».

Eva Valcárcel López (ed.), Hispanoamérica en sus textos: ciclo de conferencias (A Coruña, 1992), A Coruña: Universidade da Coruña. Servizo de Publicacións, 85-96. 
Pozuelo Yvancos 2013: José María Pozuelo Yvancos. Vargas Llosa y Joseph Conrad: dos miradas al colonialismo (Conferencia impartida en Universidad de Valladolid (UVA) el 9 de noviembre de 2012). Alicante: Biblioteca Virtual Miguel de Cervantes. Web. 12/09/2015. Quintana González 2017: Desimarie Quintana González. La reescritura del héroe en El sueño del celta de Mario Vargas Llosa. Puerto Rico: University of Puerto Rico, Rio Piedras, ProQuest Dissertations Publishing. Web. 23/12/2019.

Sekulić 2017: Mirjana Sekulić. «Pristupi temi kolonijalizma u romanu Keltov san Marija Vargasa Ljose». Aleksandar Jerkov \& Ksenija Vulović (eds.), Književni plamen Marija Vargas Ljose, Beograd: Kosmos izdavaštvo / Podgorica: Nova knjiga, 144-161.

Servije 2005: Žan Servije. Istorija utopije. Beograd: Clio.

Todorov 2010: Cvetan Todorov. Strah od varvara. Loznica: Karpos.

Vargas Llosa 1976: Mario Vargas Llosa. «Albert Camus y la moral de los límites». Inti: Revista de literatura hispánica, 4. Web. 12/09/2015.

Vargas Llosa 1984: Mario Vargas Llosa. «El arte de mentir». Revista de la Universidad de México, 42: 1-4. Web. 02/06/2015.

Vargas Llosa 2000: Mario Vargas Llosa. «Un mundo sin novelas». Letras libres, 22: 38-44. Web. 04/06/2015.

Vargas Llosa 2001: Mario Vargas Llosa. «Las raíces de lo humano». Letras libres, 36: 18-23. Web. 04/06/2015.

Vargas Llosa 2003: Mario Vargas Llosa. «Soy un utópico en todo menos en política». Entrevistado por Fietta Jarque, El País, 29.03.2003. Web. 04/06/2015.

Vargas Llosa 2007: Mario Vargas Llosa. La verdad de las mentiras. Madrid:

Punto de lectura.

Vargas Llosa 2010a: Mario Vargas Llosa. El sueño del celta. Madrid: Alfaguara.

Vargas Llosa 2010b: Mario Vargas Llosa. «La maldad». El País, 24.10.2010. Web. 04/06/2015.

Vargas Llosa 2010c: Mario. Elogio de la lectura y la ficción (Discurso Premio Nobel). Web. 04/06/2015.

Vargas Llosa 2011: Mario Vargas Llosa. El viaje a la ficción. El mundo de Juan Carlos Onetti, Madrid: Santillana Ediciones.

Weldt-Basson 2013: Helene Carol Weldt-Basson. «El sueño del Celta: Poscolonial Vargas Llosa». Helene Carol Weldt Basson (ed.), Redefining Latin American Historical Fiction, New York: Palgrave Macmillan, 231-247. 
Wolfzettel 2005: Friedrich Wolfzettel. «Relato de viaje y estructura mítica». Leonardo Romero Tobar \& Patricia Almarcegui Elduayen (coords.), Los libros de viaje: realidad vivida y género literario, Madrid: Akal / Universidad Internacional de Andalucía, 10-24.

\section{BARBARISM AND AWAKENING OF THE HERO IN THE NOVEL THE DREAM OF THE CELT BY MARIO VARGAS LLOSA}

\section{Summary}

In this paper, several aspects of the novel The Dream of Celt (2010) by Mario Vargas Llosa are interpreted, taking into consideration postcolonial theories and the attitudes of the Peruvian writer on different issues, expressed in his essays, interviews and articles. The starting point is Vargas Llosa's idea about literature and history, the writer's moral duty to history, along with the need to overcome conformism. Based on this, we question how the novel The Dream of the Celt initiates several questions about colonialism, the boundaries between barbarism and civilization, the awakening of heroes, the possibility of achieving freedom, etc. The article focuses on the complex colonial reality presented in the novel, deepening the questioning of responsibilities and victims of the great civilizing mission in Congo and Amazonia. The protagonist is interpreted in relation to the voyage, physical and symbolic, observing the changes produced in his personality by the interactions in the colonial environment. Reflections on the identity and behavior of the protagonist lead to conclusions about the conception of the hero in this novel, as well as to an understanding of the role that Vargas Llosa gives to fiction in relation to collective and personal freedom.

Keywords: Mario Vargas Llosa, The dream of the celt, colonialism, barbarism, heroe, liberty, literature. 